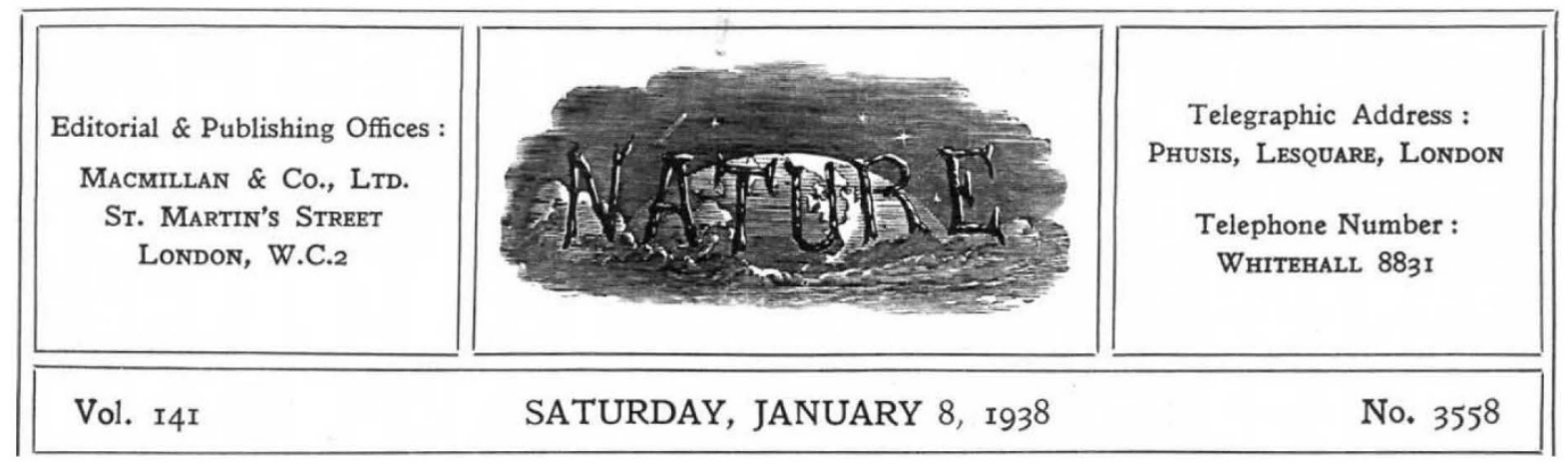

\title{
Training and Employment of University Graduates
}

$I^{\mathrm{F}}$ happily unemployment of graduates is less serious in Great Britain than in some other European countries, it has been sufficiently widespread to offer obstacles to the work of the Society for the Protection of Science and Learning in finding occupation for displaced men of science from abroad, apart from the existence of a by no means negligible amount of wastage and misplacement of young graduates of our own universities. Indeed, the position led the University Grants Committee in its last report to suggest that the universities themselves should consider not merely the question of the appropriate number of university students in relation to the population of the country as a whole, but also that of the appropriate number for any particular university. Granting that a university should not be too preoccupied with problems of purely professional vocations for its students, it should none the less face the question whether the time has arrived, or is approaching, when additions to its numbers will tend to impair the quality of the instruction and the value of the training for life it sought to give.

For these reasons, the inquiry on unemployment among graduates, and the study of the proposals for diminishing unemployment in intellectual professions, which has already been initiated by the Committee on Intellectual Co-operation of the League of Nations, is of no less interest in Great Britain than elsewhere; while W. M. Kotschnig's recent study of unemployment in the learned professions* is also a valuable contribution. The case he presents for real educational and occupational planning in our changing society as the only solution of this difficult problem deserves careful consideration, reinforced as it is from other

* London: Oxford University Press, 1937. 128. 6d. net. quarters of the industrial world by the suggestion that industry should consider more closely not merely qualitative but also quantitative requirements in regard to recruitment generally.

It can scarcely be denied that neither the universities nor professional associations of scientific workers, despite serious warnings, have given anything like the attention to this question that it demands. The report on graduate employment recently issued by the National Union of Students, to which reference was made in discussions at the British Association meetings at Nottingham, brings together in this field a number of suggestions or proposals which require attention and action by professional associations as well as by university authorities.

This report, which brings out the fact that in Great Britain the question of misemployment among graduates is as important, if not more important, than that of actual unemployment, reveals the meagreness and inadequacy of existing statistics and the complete absence of planning or control over the numbers entering various branches of study, as well as the ignorance on the part of students proceeding to a university of conditions in the employment market. The most serious criticism in the report is, in fact, that of the lack of guidance and help available at the universities for placing students in careers. Even where appointment boards or officers are to be found, their organization often leaves much to be desired. Contact with students is imperfect, and with industry, commerce and the professions is often poor.

Many who have attempted to recruit university graduates, particularly for any of the less usual openings, will agree that much of this criticism is 
well founded. It is no uncommon experience to find that after approaches to the universities appointments boards or advertisements in the appropriate scientific or technical journals have drawn blank, promising candidates have been encountered accidentally, who, like the professors of their particular faculty, were quite unaware of the existence of the vacancy. Quite apart from the fact that the outlook of graduates on the sphere of employment is often unnecessarily narrow, such experiences are common enough to indicate not merely the failure of graduates to look round them intelligently but also an amazing lack of contact between the appointments boards and the different faculties or departments the students of which it is their function to place.

There can, of course, be no question of value of the appointments board when well organized and properly run. An efficient board rapidly builds up a reputation for supplying candidates of the right type; and this is as valuable to the employer as to the graduates it places. Accordingly, the highly constructive suggestions in this matter, which are outlined in an appendix to the report referred to, merit close attention by all concerned with the placing of graduates in employment; for the establishment of efficient appointment boards must inevitably precede the consideration of the quantitative aspect of the question. These suggestions show clearly that at the present time the problem is not so much one of finding posts for graduates but of finding graduates to fill the existing vacancies.

One of the first results of a really efficient appointments organization would be not only to co-ordinate the spasmodic and often haphazard recommendations and efforts of individual professors and teachers, and to promote the supply of candidates in whom due weight was given to the other qualities besides the academic which they possess, but also to facilitate the collection of accurate and comprehensive information. The functions of the organization should, in fact, include a survey of the whole field of potential employment for university graduates, and the establishment and maintenance of contact with employers' associations, professional institutions and organizations and the like.

Information regarding the qualifications and personnel required for different careers, as well as of the nature and conditions of the work, salary scales and prospects, is frequently readily obtainable, but corresponding information regarding the overcrowding of a particular occupation, new developments and tendencies is often deficient and inaccurate, and in many places the means of making even the existing information really available to students early in their university career appear to be in need of improvement. It is suggested, accordingly, that a handbook on the lines of the "Handbook on Careers for Graduates and Students", which is published by the University of London Appointments Board, might be issued by each appointments board.

Obviously there is room in this particular field for effective co-operation between the appointments boards of different universities. Even if certain universities desired to expand the information regarding the particular occupations for which they specially prepare students, there would appear to be no reason why such a handbook should not be prepared on behalf of all the universities. Not only should a mere comprehensive handbook be obtainable in this way, but also co-operation should offer substantial financial savings.

Whether there is need for the different subcommittees suggested in the report to deal with technical appointments, teaching, professional, Government appointments and commerce, etc., may well be a matter of opinion. Much depends on obtaining men of the right type of personality, mature experience and with something of a flare for establishing contacts to serve the board. Appointments officers of the right type could probably be relied upon to take care of the requisite internal as well as external contacts, though it may sometimes be advisable for the university to institute some means of stimulating the use of the machinery provided in the boards' organizations, so as to bring together all those interested in placing graduates whether of a special faculty or not.

As to the wisdom of the further suggestions regarding contact between students, and between the appointments officers of different universities, there can scarcely be any difference of opinion, though there are other ways of securing contact with students than by representation on the boards. Such co-ordination and organization are essential if statistical information is to be collected in standardized form on the numpers or students in each faculty, the potential output of the university for different careers and the numbers of students leaving or who have left the university, and the nature and extent of unemployment among them. 
Valuable, however, as are such statistics as a preliminary to planning the wiser use of university education on the community, we must guard against the mistake of allowing the university authorities or the students themselves to be preoccupied excessively with the professional prospects of later life. The effective employment of university graduates is a matter of much moment to the community as a whole as well as to the individuals concerned, since the appropriate use of talent to a large extent governs the pace of social progress. This is one reason for regarding with concern the comparative neglect of university graduates in the local government service of the country. None the less, we must be at pains to reconcile the objective of the best training for a vocation in life with that of the best training for life itself.

Once again, therefore, we are brought back to the question of the true purpose of a university, and even here it seems that a university appoint- ments officer might well make a valuable contribution. His contacts with the industrial and commercial world should enable him to supply timely warning about the evils of premature or excessive specialization, and to insist on the need for men and women with a wide outlook, sense of values and cultural interests so strongly stressed in recent discussions. It should enable him too, perhaps, in his contact with students, to inspire them with a sense of responsibility for service which, by bringing out the fundamental meaning of vocation, may rob vocational training of its dangers. Nor should he lack the opportunity to give timely warnings as to the importance of cultivating human interests and utilizing to the full the opportunities which the social and athletic activities of college life afford of developing initiative, personality and the capacity to cooperate, upon which, as much as on intellectual attainment, depend alike individual success and the fullest meed of service to the community.

\section{Growth-Regulating Substances in Plants}

\section{Phytohormones}

By, F. W. Went and Kenneth V. Thimann. (Experimental Biology Monographs.) Pp. xi+294. (New York: The Macmillan Co.) 17s. net.

$\mathrm{T}$ HIS book will prove very valuable as it reviews admirably a field in which the contributions have recently been so numerous that it is difficult to follow them all. (The authors give references to seventy-four papers on plant hormones for 1936 alone.) This rapid output is no doubt due to the discovery by Kögl and Kostermans (Z. physiol. Chem., 235, 201) in 1934 that indole-3-acetic acid, sometimes called 'heteroauxin', a substance which can be synthesized, acts on plant growth in very nearly the same way as the natural growth-hormone or 'auxin': for this has provided wonderful opportunities for experimenting. But unfortunately, as the authors point out, the quality of some of this recent work has not been so good as that of the earlier work on the growth-hormone : indeed, some recent contributions have shown that the investigators responsible for them neither know what has been done already nor understand what are the problems at issue. The book should, therefore, be very useful, since it reviews critically the subject of the hormones of higher plants and shows up the main problems clearly : indeed it is one of the chief attractions of the book that it looks to the future as much as to the past. The authors include also summary statements of many interesting unpublished results, and although an excellent historical survey of the same field by Boysen Jensen entitled "Die Wuchsstofftheorie" appeared in 1935, progress has been so rapid that they have been able to include a great deal that was not in the earlier book.

Boysen Jensen has claimed ("Die Wuchsstofftheorie", p. 12) that in his well-known experiments of 1910, 1911 and 1913, from which the modern study of the growth-hormone has mainly developed, he proved that there exists a growthpromoting substance in the oat coleoptile during the phototropic excitation, and that it is by the movement of this substance that the phototropic stimulus can be transmitted (as he showed) from the tip across a watery gap below. In the reviewer's opinion, this claim is justified, except that, as Went and Thimann point out, he did not show that he was dealing with a single growth-promoting substance rather than with several substances. But neither did the later experiments of Paál (Ber. bot. Ges., 32, 499 ; 1914; Jahrb. wiss. Bot., 58, 406 ; 1919) show that the growth-hormone is a single substance, in spite of what Went and Thimann say (p. 11). The important point which was missed by Boysen Jensen but established by Paál and by Söding (Ber. bot. Ges., 41, 396; 1923) is that 